\section{SAT0372 CHANGE OF SUBCLINICAL ATHEROSCLEROSIS AFTER FIVE YEARS ANTI-TNF TREATMENTS IN PSORIATIC ARTHRITIS}

Abdulsamet Erden ${ }^{1}$, Uğur Canpolat ${ }^{2}$, Oğuz Abdullah Uyaroğlü ${ }^{3}$, Cem Çöteli ${ }^{2}$, Levent Kiliç ${ }^{1}$, Ali Akdoğan ${ }^{1}$, Umut Kalyoncu ${ }^{1}$, Omer Karadag ${ }^{1}$, Ali insan Ertenli ${ }^{1}$, Sedat Kiraz ${ }^{1}$, Kudret Aytemir ${ }^{2}$, Sule Apraş Bilgen ${ }^{1} .{ }^{1}$ Hacettepe University Faculty of Medicine, Department of Internal Medicine, Division of Rheumatology, Ankara, Turkey; ${ }^{2}$ Hacettepe University Faculty of Medicine, Department of Cardiology, Ankara, Turkey; ${ }^{3}$ Hacettepe University Faculty of Medicine, Department of Internal Medicine, Ankara, Turkey

Background: Although cardiovascular (CV) diseases are very common in inflammatory arthritis like psoriatic arthritis (PsA), long-term impact of medication on CV outcomes is lacking.

Objectives: The aim of our study was to evaluate the long-term effects of anti-TNF-a drugs on subclinical atherosclerosis assessed by the flowmediated dilatation (FMD) and carotid intima media thickness (IMT).

Methods: A total of 30 patients with PsA according to classification of psoriatic arthritis (CASPAR) criteria1 and 28 healthy controls were enrolled in this cross-sectional study between June 2011-July 2012. 22 out of 30 PsA patients completed the study. Demographic data (sex, age), PsA and psoriasis duration, joint pattern (monoarthritis, oligoarthritis or polyarthritis) and other PsA involvements (nail, enthesis, dactilytis) were noted. Tender joint count, swollen joint count and disease activity score (DAS)-28 were used for joint activity assessment. Erythrocyte sedimentation rate (ESR) and C-reactive protein (CRP) were used for acute phase reactants. Sex and age matched healthy controls were selected as the control group for this study. Flow mediated dilatation (FMD) from brachial artery and carotid intima media thickness (IMT) were measured by an experienced cardiologist both at initial and 5-year follow-up visits.

Results: Psoriasis duration of PsA patients was $180 \pm 114$ months. PsA disease duration was $108 \pm 33$ months. The mean duration between two evaluations was $62 \pm 9$ months. At first evaluation, $14(63.6 \%)$ patients had peripheral joint, $1(4.5 \%)$ patient had axial, and $7(31.8 \%)$ patients had both peripheral and axial involvement among patients. Dactilytis in 6 $(27.3 \%)$, enthesis in $7(31.8 \%)$ and nail in $12(54.5 \%)$ patients were other clinical involvements. FMD\% was lower in PsA patients than healthy controls $[9.3 \pm 3.9$ vs $12.9 \pm 1.8, \quad p<0.001]$ and carotid IMT was more obvious in PsA patients than healthy controls $[0.64 \pm 0.17$ vs 0.54 $\pm 0.09, p=0.017]$ (Figure). All PsA patients used anti-TNF alpha treatment during the follow-up period. $68.1 \%$ of the PsA patients were in remission during the control. At 5-year follow-up visits, there was no $\mathrm{CV}$ event in study groups. However, FMD\% was lower in PsA patients than healthy controls [7.6 \pm 4.8 vs $12.9 \pm 1.8, p<0.001]$ and carotid IMT was also similar between PsA patients and healthy controls $[0.61 \pm 0.33$ vs $0.54 \pm 0.09$, $\mathrm{p}=0.306]$. After 5 -year follow-up visits, there was no statistically significant difference in FMD\% compared to baseline $[p=0.254] . \triangle F M D \%$ was found to be moderately correlated with the $\triangle B A S D A I(r=-0.45)$.

Conclusion: Our results showed that there was a significant impact of anti-TNF-a drugs on progression of subclinical atherosclerosis at the vascular wall level, but no impact on the endothelial dysfunction. Further large-scale randomized studies are needed to confirm our findings.

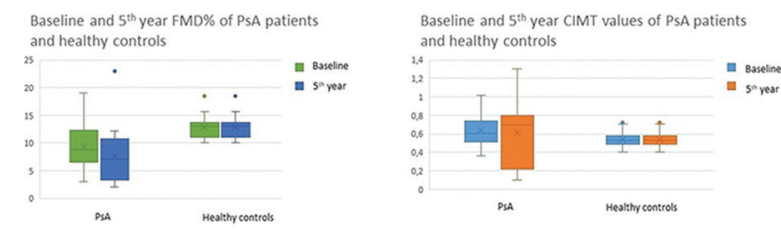

Figure.

Disclosure of Interests: Abdulsamet Erden: None declared, Uğur Canpolat: None declared, Oğuz Abdullah Uyaroğlu: None declared, Cem Çöteli: None declared, Levent Kiliç: None declared, Ali Akdoğan: None declared, Umut Kalyoncu Grant/research support from: MSD, Roche, UCB, Novartis and Pfizer, Consultant for: MSD, Abbvie, Roche, UCB, Novartis, Pfizer and Abdi Ibrahim, Speakers bureau: MSD, Abbvie, Roche, UCB, Novartis, Pfizer and Abdi Ibrahim, Omer Karadag: None declared, Ali İhsan Ertenli: None declared, Sedat Kiraz: None declared, Kudret Aytemir: None declared, Şule Apraş Bilgen: None declared

DOI: 10.1136/annrheumdis-2019-eular.6044

\section{SAT0373 EFFECT OF FILGOTINIB ON PATIENT-REPORTED OUTCOMES IN ACTIVE PSORIATIC ARTHRITIS: RESULTS FROM EQUATOR, A RANDOMIZED, PHASE 2 STUDY}

Laura C. Coates ${ }^{1}$, Philip J. Mease ${ }^{2}$, Dafna D. Gladman ${ }^{3}$, Filip van den Bosch ${ }^{4}$, Chantal Tasset $^{5}$, Luc Meuleners ${ }^{5}$, Robin Besuyen ${ }^{6}$, Jingjing Gao ${ }^{7}$, Mona Trivedi ${ }^{7}$, Thijs Hendrikx ${ }^{6}$, Philip Helliwell ${ }^{8}$. 1 University of Oxford, Oxford, United Kingdom;

${ }^{2}$ Swedish Medical Center/Providence St Joseph Health and University of Washington, Seattle, United States of America; ${ }^{3}$ University of Toronto and Krembil Research Institute, Toronto Western Hospital, Toronto, Canada; ${ }^{4}$ Ghent University Hospital, Ghent, Belgium; ${ }^{5}$ Galapagos NV, Mechelen, Belgium; ${ }^{6}$ Galapagos BV, Leiden, Netherlands; ${ }^{7}$ Gilead Sciences, Inc., Foster City, United States of America; ${ }^{8}$ Leeds Institute of Rheumatic and Musculoskeletal Medicine, Leeds, United Kingdom

Background: Filgotinib (FIL) is an oral, selective Janus kinase 1 inhibitor under clinical investigation in a number of inflammatory diseases. FIL sig nificantly improved multiple disease domains vs placebo (PBO) in patients with active psoriatic arthritis (PsA) in the multicenter, double-blind, phase 2 EQUATOR trial (NCT03101670) [1].

Objectives: To evaluate the effect of FIL vs PBO on patient reported outcomes (PROs) in EQUATOR and the extent to which effects on composite disease endpoints translate to clinically relevant improvements for patients.

Methods: Patients were randomized 1:1 to FIL $200 \mathrm{mg}$ or PBO once daily for 16 weeks [1]. Patient's Global Assessment of Disease Activity (PtGADA), pain intensity (visual analog scale), Pruritus Numerical Rating Scale (NRS), Health Assessment Questionnaire Disability Index (HAQ-DI), 36-Item Short Form Survey (SF-36) Physical Component Summary (PCS) and Mental Component Summary (MCS), and Functional Assessment of Chronic Illness Therapy-Fatigue scale (FACIT-F) were assessed at week 16. Analysis of covariance was used to compare changes from baseline in outcomes between groups. Proportions of patients achieving normative PRO scores or minimal clinically important differences (MCIDs) were compared using Cochran-Mantel-Haenszel tests [2, 3].

Results: FIL significantly improved multiple PROs vs PBO at week 16 (Table). Proportions of patients reaching normative PRO values for FACIT-F and SF-36 PCS ( $=40$ or 50 , respectively), and achieving MCIDs in HAQ-DI and SF 36 PCS, were significantly greater for FIL vs PBO (Table). Significant improvement in $6 / 8$ SF 36 domains was observed at week 16 with FIL vs PBO (Fig a). Improvement in most individual FACIT $\mathrm{F}$ items was also observed (Fig b).

Conclusion: In EQUATOR, FIL-treated patients with active PsA reported greater and clinically meaningful improvements in most PROs at week 16 vs $\mathrm{PBO}$, mirroring improvements previously reported with FIL in disease activity measures [1].

\begin{tabular}{|c|c|c|c|c|c|}
\hline \multicolumn{2}{|l|}{ Week 16} & FIL $(n=65)$ & PBO (n=66) & $\begin{array}{c}\text { Treatment } \\
\text { difference }(95 \% \mathrm{Cl})\end{array}$ & $\mathbf{p}$ \\
\hline \multicolumn{6}{|c|}{ Mean change from baseline } \\
\hline \multicolumn{2}{|l|}{ PtGADA (mm) } & $-27.2(22.1)$ & $-13.5(25.8)$ & $-15.2^{\mathrm{a}}(-22.3,-8.1)$ & $<0.0001$ \\
\hline \multicolumn{2}{|l|}{ Pain (mm) } & $-31.6(21.3)$ & $-11.1(29.7)$ & $-18.9^{\mathrm{a}}(-26.7,-11.1)$ & $<0.0001$ \\
\hline \multicolumn{2}{|l|}{ Pruritus NRS } & $-2.5(2.1)$ & $-0.6(2.2)$ & $-2.2^{\mathrm{a}}(-3.1,-1.4)$ & $<0.0001$ \\
\hline \multicolumn{2}{|l|}{ HAQ-DI } & $-0.6(0.5)$ & $-0.3(0.5)$ & $-0.3^{\mathrm{a}}(-0.4,-0.1)$ & 0.0009 \\
\hline \multicolumn{2}{|l|}{ SF-36 PCS } & $7.4(6.6)$ & $2.4(6.6)$ & $4.7^{a}(2.6,6.8)$ & $<0.0001$ \\
\hline \multicolumn{2}{|l|}{ SF-36 MCS } & $4.3(8.3)$ & $3.2(9.2)$ & $1.2^{\mathrm{a}}(-1.7,4.0)$ & 0.4128 \\
\hline \multicolumn{2}{|l|}{ FACIT-F } & $8.2(7.3)$ & $5.5(8.1)$ & $3.2^{\mathrm{a}}(0.8,5.5)$ & 0.0086 \\
\hline \multicolumn{6}{|c|}{ Response rate, $\mathrm{n} / \mathrm{N}$ (\%) } \\
\hline HAQ-DI & $M C I D \geq 0.35$ & $41 / 63(65)$ & $26 / 62(42)$ & $23.2^{b}(5.7,38.8)$ & 0.0085 \\
\hline \multirow[t]{2}{*}{ SF-36 PCS } & Score $\geq 50$ & $11 / 64(17)$ & $4 / 63(6)$ & $10.9^{b}(-0.7,22.5)$ & 0.0471 \\
\hline & $M C I D \geq 2.5$ & $49 / 65(75)$ & 26/66 (39) & $36.0^{b}(19.2,50.0)$ & $<0.0001$ \\
\hline \multirow[t]{2}{*}{ SF-36 MCS } & Score $\geq 50$ & $13 / 46(28)$ & $14 / 47(30)$ & $-1.5^{b}(-19.4,16.6)$ & 0.9879 \\
\hline & $M C I D \geq 2.5$ & $32 / 65$ (49) & $40 / 66(61)$ & $-11.4^{b}(-27.4,5.5)$ & 0.2607 \\
\hline \multirow[t]{2}{*}{ FACIT-F } & Score $\geq 40$ & $18 / 58(31)$ & $7 / 57(12)$ & $18.7^{6}(3.6,33.0)$ & 0.0105 \\
\hline & $M C I D \geq 4$ & $43 / 65(66)$ & $37 / 66(56)$ & $10.1^{b}(-6.5,25.9)$ & 0.1921 \\
\hline
\end{tabular}

Least-squares mean. ${ }^{b}$ Arithmetic mean.

$\mathrm{Cl}$, confidence interva

\section{REFERENCES}

[1] Mease P, et al. Lancet 2018;392:2367-77.

[2] Mease P, et al. J Rheumatol 2011;38:2461-5. 

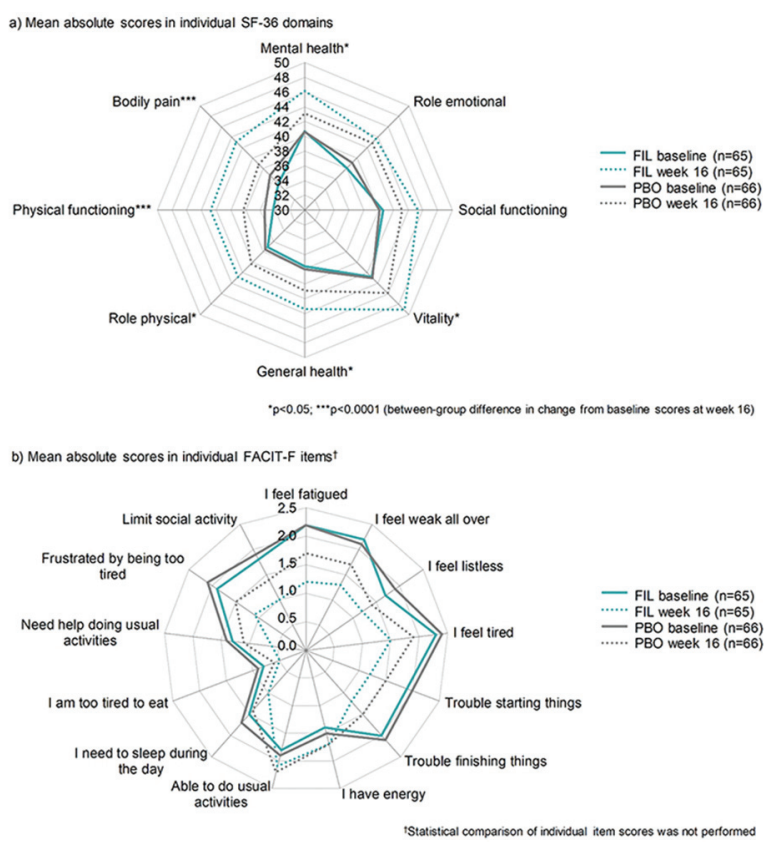

[3] Genovese M, et al. Arthritis Res Ther 2018;20:57.

Acknowledgement: This study was funded by Galapagos NV (Mechelen, Belgium). Medical writing support was provided by Alice Wareham PhD, CMPP (Aspire Scientific Ltd, Bollington, UK) and funded by Galapagos NV.

Disclosure of Interests: Laura C Coates Grant/research support from: AbbVie, Celgene, Lilly, Novartis and Pfizer, Consultant for: AbbVie, Amgen, BMS, Celgene, Galapagos, Gilead Sciences Inc., Janssen, Lilly, Novartis, Pfizer, Prothena Corp and UCB, Philip J Mease Grant/research support from: AbbVie, Amgen, BMS, Celgene, Janssen, Lilly, Novartis, Pfizer, SUN and UCB, Consultant for: AbbVie, Amgen, BMS, Galapagos, Gilead Sciences, Inc., Janssen, Lilly, Novartis, Pfizer, SUN and UCB, Speakers bureau: AbbVie, Amgen, BMS, Celgene, Genentech, Janssen, Lilly, Novartis, Pfizer and UCB, Dafna D Gladman Grant/research support from: AbbVie, Amgen, Celgene, Lilly, Novartis, Pfizer, and UCB, Consultant for: AbbVie, Amgen, BMS, Celgene, Galapagos, Gilead, Janssen, Lilly, Novartis, Pfizer, and UCB, Filip van den Bosch Consultant for: AbbVie, BMS, Galapagos, Janssen, Lilly, Merck, Novartis, Pfizer and UCB, Speakers bureau: AbbVie, BMS, Janssen, Lilly, Merck, Novartis, Pfizer and UCB., Chantal Tasset Shareholder of: Warrants from Galapagos, Employee of: Galapagos, Luc Meuleners Shareholder of: Warrants from Galapagos, Employee of: Galapagos, Robin Besuyen Shareholder of: Warrants from Galapagos, Employee of: Galapagos, Jingjing Gao Shareholder of: AbbVie and Gilead Sciences, Inc., Employee of: Gilead Sciences, Inc., Mona Trivedi Shareholder of: Amgen and Gilead Sciences, Inc., Employee of: Gilead Sciences, Inc., Thijs Hendrikx Shareholder of: Warrants from Galapagos, Employee of: Galapagos, Philip Helliwell Grant/ research support from: Paid to charity: from AbbVie, Janssen and Novartis, Consultant for: Paid to charity: from AbbVie, Amgen, Pfizer, and UCB and Celgene. Paid to self: from Celgene and Galapagos DOI: 10.1136/annrheumdis-2019-eular.6108

\section{SAT0374 IXEKIZUMAB, WITH OR WITHOUT CONCOMITANT METHOTREXATE, IMPROVES THE SIGNS AND SYMPTOMS OF PSA FOR UP TO 52 WEEKS OF TREATMENT}

Bernard Combe ${ }^{1}$, Tsen-Fang Tsai ${ }^{2}$, Satish Odhav ${ }^{3}$, J. Eugene Huffstutter ${ }^{4}$, Aubrey Trevelin Sprabery ${ }^{5}$, Chen-Yen Lin ${ }^{5}$, So Young Park ${ }^{5}$, Matthew Hufford ${ }^{5}$, Peter Nash ${ }^{6} .{ }^{1}$ University of Montpellier, Montpellier, France; ${ }^{2}$ National Taiwan University, Taipei, Taiwan, Republic of China; ${ }^{3}$ Arthritis Clinic, Jackson, United States of America; ${ }^{4}$ Arthritis Associates, Hixson, United States of America; ${ }^{5}$ Eli Lilly and Company, Indianapolis, United States of America; ${ }^{6}$ University of Queensland, Brisbane, Australia

Background: Ixekizumab (IXE) is a high affinity monoclonal antibody selectively targeting interleukin (IL)-17A. It was previously demonstrated that IXE, with or without concomitant methotrexate (MTX), was superior to placebo (PBO) in improving the signs and symptoms of patients with psoriatic arthritis (PsA) for up to 24 weeks ${ }^{1,2}$.

Objectives: To evaluate the efficacy of IXE, with or without continuous concomitant MTX, for up to 52 weeks of treatment in patients with active PsA.

Methods: Patients with active PsA who were biologic naïve (SPIRIT-P1, NCT01695239) or had prior inadequate response or intolerance to tumour necrosis factor inhibitors (SPIRIT-P2; NCT02349295) were randomised to PBO ( $\mathrm{N}=224), 80 \mathrm{mg}$ IXE every 4 weeks (IXEQ4W, $\mathrm{N}=229$ ) or every 2 weeks (IXEQ2W, $\mathrm{N}=226$ ), after a $160 \mathrm{mg}$ starting dose. In this post-hoc analysis, efficacy was assessed up to Week 52 for the following two subgroups: (i) patients who were treated with IXE as monotherapy i.e. no concomitant conventional disease-modifying anti-rheumatic drugs and (ii) patients who received constant dose of MTX from Weeks 0 to 52 . Patients who had MTX dose change were excluded. Efficacy outcome measurements included American College of Rheumatology (ACR) 20/50/ 70 responses, minimal disease activity (MDA), and disease activity in psoriatic arthritis (DAPSA) low disease activity (LDA) (score $\leq 14$ ). Patients who discontinued from treatment before Week 52 were included in the analysis. Missing values were imputed using non-responder imputation. All analyses were done post-hoc.

Results: Among patients randomised to IXE at Week 0, 177 (38.9\%) patients were treated with IXE monotherapy while 183 (40.2\%) patients received constant dose of MTX up to Week 52. The average MTX dose was $15.7 \mathrm{mg} /$ week and $16.0 \mathrm{mg} /$ week for IXEQ4W and IXEQ2W, respectively. Week 52 results are presented in Table 1 . At Week 52, similar results were observed between the two groups of patients for the different disease activity measures (ACR, MDA, and DAPSA LDA) and there was also a trend for a numerical higher proportion of patients achieving ACR responses with IXE monotherapy compared to patients with concomitant MTX use. Over time (Weeks 0-52), ACR 20, 50, and 70 response rates increased from baseline and were largely similar between the two subgroups (data not shown).

Conclusion: In this post-hoc analysis, IXE treatment showed sustained efficacy in patients with PSA up to one year of treatment, with or without concomitant MTX therapy.

\section{REFERENCES}

[1] Nash P, et al. RMD Open. 2018;4(2):e000692.

[2] Coates LC, et al. RMD Open. 2017;3(2):e000567.

Table 1. Efficacy Outcomes at Week 52

\begin{tabular}{lcccc}
\hline & \multicolumn{2}{c}{$\begin{array}{c}\text { IXEQ4W } \\
\text { N=229 }\end{array}$} & \multicolumn{2}{c}{$\begin{array}{c}\text { IXEQ2W } \\
\text { N=226 }\end{array}$} \\
\hline Concomitant Medication: & None $(\mathrm{n}=95)$ & MTX $(\mathrm{n}=85)$ & None $(\mathrm{n}=82)$ & MTX $(\mathrm{n}=98)$ \\
\hline ACR 20 & $66.3 \%$ & $55.3 \%$ & $63.4 \%$ & $55.1 \%$ \\
ACR 50 & $48.4 \%$ & $38.8 \%$ & $48.8 \%$ & $38.8 \%$ \\
ACR 70 & $35.8 \%$ & $27.1 \%$ & $35.4 \%$ & $23.5 \%$ \\
DAPSA LDA* & $52.6 \%$ & $52.9 \%$ & $54.9 \%$ & $41.2 \%$ \\
MDA & $38.9 \%$ & $35.3 \%$ & $36.6 \%$ & $22.7 \%$ \\
\hline
\end{tabular}

${ }^{*}$ score $\leq 14$

Disclosure of Interests: Bernard Combe Consultant for: Abbvie, BristolMyers Squibb, Gilead, Janssen, Eli Lilly, MSD, Novartis, Pfizer, RocheChugai, Sanofi, UCB, Tsen-Fang Tsai Consultant for: AbbVie, Boehringer Ingelheim, Celgene, EliLilly, GSK-Stiefel, Janssen-Cilag, Novartis, Pfizer, Speakers bureau: AbbVie, EliLilly, Janssen-Cilag, Novartis, Pfizer, Satish Odhav Grant/research support from: AbbVie, Ardea Biosciences, AstraZeneca, BMS, Celgene Corporation, Centocor, Eli Lilly and Company, Galapagos, Genentech, GSK, Human Genome Sciences, Janssen, Merck, Mesoblast, Novartis, Novo Nordisk, Pfizer, Roche, Sanofi-Aventis, Takeda Pharmaceuticals, UCB, and Vertex Pharmaceuticals, Consultant for: AbbVie, Ardea Biosciences, AstraZeneca, BMS, Celgene Corporation, Centocor, Eli Lilly and Company, Galapagos, Genentech, GSK, Human Genome Sciences, Janssen, Merck, Mesoblast, Novartis, Novo Nordisk, Pfizer, Roche, Sanofi-Aventis, Takeda Pharmaceuticals, UCB, and Vertex Pharmaceuticals, Speakers bureau: AbbVie, Ardea Biosciences, AstraZeneca, BMS, Celgene Corporation, Centocor, Eli Lilly and Company, Galapagos, Genentech, GSK, Human Genome Sciences, Janssen, Merck Mesoblast, Novartis, Novo Nordisk, Pfizer, Roche, Sanofi-Aventis, Takeda Pharmaceuticals, UCB, and Vertex Pharmaceuticals, J. Eugene Huffstutter Consultant for: Eli Lilly, Speakers bureau: Janssen, Genentech, Pfizer, Lilly, Regeneron, Aubrey Trevelin Sprabery Shareholder of: Eli Lilly and Company, Employee of: Eli Lilly and Company, Chen-Yen Lin Shareholder of: Eli Lilly and Company, Employee of: Eli Lilly and Company, 